\title{
CARACTERIZAÇÃO BIOQUÍMICA DE UMA ENZIMA EXTRA-CELULAR DE UM FUNGO TERMO-TOLERANTE
}

\author{
BIOCHEMICAL CHARACTERIZATION OF AN EXTRA-
} CELLULAR ENZYME OF A HEAT-TOLERANT FUNGUS

WILLIAM BRANDANI DA SILVA ${ }^{1}$

ROSANE MARINA PERALTA ${ }^{2}$

1 Professor da UNIPAR

2 Professora da UEM

\section{RESUMO}

Este trabalho tem por objetivo caracterizar bioquimicamente uma enzima amilásica extracelular de um fungo de solo mesófilo (Aspergillus).

Palavras-chave: fungo; amilase; caracterização bioquímica

\section{Introdução}

As enzimas amilolíticas, hoje, têm um importante papel industrial. Elas são usadas na produção de xarope de glucose, pela hidrólise do amido da glucose, o qual geralmente é usado na produção do etanol.

Enzimas amilolíticas de fungos termófilos e termotolerantes têm sido 
procuradas, pois há passos nos processos industriais que necessitam de enzimas resistentes a temperaturas mais elevadas.

O fungo filamentoso Aspergilus fumigatus é um fungo termotolerante. Ele produz duas enzimas amilolíticas que foram pouco pesquisadas até o presente momento. Uma cepa foi isolada pela Dra. Rosane Peralta e uma caracterização inicial de suas enzimas extracelulares realizada (PERALTA e DOMINGUES, 1993; PLANCHOT e COLONNA, 1995; HIZUKURI et al., 1988).

\section{Materiais e métodos}

\subsection{Microorganismo}

O fungo Aspergillus fumigatus usado foi isolado durante um programa de seleção de microorganismo do solo produtor de amilase (PERALTA e DOMINGUES, 1993) e armazenado em meio ágar-batata a $4^{\circ} \mathrm{C}$.

\subsubsection{Condições de crescimento}

Produção de enzima crua em cultura líquida. A suspensão de esporos foi usada como inóculo erlenmeyer para $250 \mathrm{ml}$ de meio de cultura Voguel (MONTENECOURT e EVELEIGH, 1977) e farelo de aveia 2\% dissolvido no meio. $\mathrm{O}$ organismo foi cultivado a $30^{\circ} \mathrm{C}$ sem agitação. Depois de 6 dias, o micélio foi filtrado sobre papel filtro e estocado a $-15^{\circ} \mathrm{C}$ para uso posterior. Purificação de glucoamilase extracelular. O filtrado cru $(100 \mathrm{ml})$ foi precipitado com sulfato de amônio, a $75 \%$ de saturação e a $4^{\circ} \mathrm{C}$. Colocou-se o precipitado (do filtrado cru da cultura citada acima e precipitado com sulfato de amônio) para centrifugar (11000 g, 30 minutos, $-40^{\circ} \mathrm{C}$ ), dissolvido em tampão $\mathrm{KH}_{2} \mathrm{PO}^{4-} \mathrm{NaOH}, 50 \mathrm{mM}$, pH 6, e o centrifugado insolúvel foi removido (ressuspendido) e dialisado em membrana de celulose porosa. Passou-se o sobrenadante (volume $15 \mathrm{ml}$ ) por uma coluna de DEAE - celulose (50 ml), equilibrado com $100 \mathrm{ml}$ de tampão acetato, depois eluído com um gradiente de $0 \mathrm{mM}$ a $300 \mathrm{mM}$ de cloreto de sódio. Frações de $10 \mathrm{~mL}$ foram coletadas.

\subsubsection{Testes enzimáticos}

A atividade de digestão de amido das enzimas do filtrado de cultura foi testada de dois diferentes modos: 
2.1.2.1 Teste da glucoamilase: mede a liberação de glicose do amido pelo teste de glicose-oxidase-peroxidase (BERGMEYER e BERNT, 1974) utilizando-se uma suspensão amido a 0,5\% em tampão $\mathrm{KH}_{2} \mathrm{PO}^{4}$ - NaOH; 50 $\mathrm{mM}$, pH6, $36^{\circ} \mathrm{C}$, por 10 minutos.

2.1.2.2 Teste de $\alpha$-amilase: A atividade dextrinizante do filtrado em cultura foi determinada pelo teste iodométrico, como descrito em Wilson e Ingledew (1982).

Em ambos os casos, amostra de enzimas são diluídas apropriadamente para manter a linearidade sobre o intervalo do teste.

\subsubsection{Cromatografia dos produtos de hidrólise}

A ação de enzima sobre amido solúvel era monitorada em papel cromatográfico em tempos de incubação fixos. A glucoamilase homogênea (um $\mathrm{ml}$ contendo 0,669 U enzimáticas) era incubada com um $\mathrm{ml}$ de amido solúvel (0,5\%) em $\mathrm{KH}^{2} \mathrm{PO}_{4}-\mathrm{NaOH}$, tampão $50 \mathrm{mM}$ pH 6. Depois de 10 minutos e de duas horas, a reação era parada, fervendo-se e estocando-se a $-4^{\circ} \mathrm{C}$, para uso posterior. Amostras (5 ml) foram colocadas sobre papel Whatmam n. 1 e a cromatografia descendente realizou-se em temperatura ambiente com um sistema de solvente, butanol, piridina e água (6-4-3) (GAILLARDY, 1953). A cromatografia foi revelada com nitrato de prata (MAYER e LARNER, 1959).

2.1.4. Determinação do conteúdo de proteínas

Estimado pelo método descrito por Lowry et al. (1951) usando albumina sérica bovina como padrão.

\subsubsection{Efeito de sais e outros reagentes}

O efeito dos sais de vários cátions, como $\mathrm{Mg}^{+2}, \mathrm{Ca}^{+2}, \mathrm{Fe}^{+3}, \mathrm{Co}^{+2}, \mathrm{Mn}^{+2}$, $\mathrm{Zn}^{+2}, \mathrm{Cu}^{+2}, \mathrm{NH}_{4}^{+}, \mathrm{Na}^{+}, \mathrm{K}^{+}, \mathrm{Pb}^{+2}$ e $\mathrm{Hg}^{+2}$ (cada um com $10 \mathrm{mM}$ e Mg com 10, 20, 50, $100 \mathrm{mM})$, e reagentes como EDTA $(10 \mathrm{mM})$, na atividade de glucoamilase, fora examinados.

Estudou-se a especificidade de substrato da enzima, a amilase purificada (item 2.1.1), em testes de atividade padrão como o descrito acima (item 2.1.2.1), com uma variedade de dissacarídeos, oligossacarídeos e polissacarídeos incubados a $36^{\circ} \mathrm{C}$ por 10 minutos. 


\subsection{Efeitos da temperatura}

A temperatura ótima de atividade enzimática foi determinada com amido solúvel para as temperaturas na faixa de 25 a $81^{\circ} \mathrm{C}$, sendo as outras condições padrões (\% de amido, pH, tempo, e tampão).

\section{3. pH ótimo}

$\mathrm{O}$ pH ótimo foi determinado usando como substrato o amido solúvel em tampão glutamato 0,05 m (pH1,A2,5), tampão alanina 0,05 m (pH 3 a 4), tampão acetato $0,05 \mathrm{~m}$ (pH 4 a 5,2), tampão citrato $0,05 \mathrm{~m}$ (pH 5 a 6) tampão fosfato (pH 6,0 a 7,0), glicina 0,05 m (pH 7,8 a 8,7) e tampão borato $0,05 \mathrm{~m}(\mathrm{pH} 8,9$ a 9,5$)$.

\subsection{Teste do glicogênio}

O percentual restante de glicogênio depois de sua hidrólise enzimática foi determinado com uma solução de iodo-iodeto mais $\mathrm{CaCl}_{2}$ saturado e determinado colorimetricamente a $460 \mathrm{~nm}$.

\subsubsection{Capacidade de hidrólise do amido cru}

Para testar a capacidade de glucoamilase sobre o amido cru, que é insolúvel em água, foi feita a hidrólise enzimática do amido usando um erlenmeyer contendo $5 \mathrm{ml}$ de amido cru (ele é preparado colocando-se o amido diretamente em água deionizada, na temperatura ambiente) e $5 \mathrm{ml}$ de amido gelatinizado (ele é preparado colocando-se o amido em água deionizada, e fervendo-se para a solubilização, tornando-se uma solução opalescente), todos a $1 \%$, sendo que nos dois casos era colocado $5 \mathrm{ml}$ de enzima diluída. A temperatura ambiente era de $27,5^{\circ} \mathrm{C}$, sob agitação de 80 r.p.m. depois dos tempos de 0,10 , 30, e 60 minutos, foi retirada uma alíquota de $2 \mathrm{ml}$ de cada vez.

Foi feito um segundo experimento com o amido cru, sendo que 30 $\mathrm{ml}$ de uma mistura de substrato mais complexo amilolítico (glucoamilase mais a $\alpha$-amilase) foi colocado em um erlenmeyer de $250 \mathrm{ml}$ (um era o 
controle e o outro continha 50 U enzimáticas), o frasco e o amido foram esterilizados e a manipulação feita em ambiente estéril, o teste realizou-se a $37^{\circ} \mathrm{C}$. Foram colhidas alíquotas de $3 \mathrm{ml}$ nos tempos 0, 12, 24 e 36 horas.

\section{Resultados}

\subsection{Produção e separação da glucoamilase}

Foi conseguida a separação das enzimas $\alpha$-amilase e glucoamilase depois de vários processos de purificação (sulfato de amônia, DEAE-celulose e diálise). A Tabela 1 apresenta o sobrenadante da cultura que foi precipitado com sulfato de amônio, em seguida passado por uma coluna de DEAE-celulose, separando as enzimas amilolíticas em duas frações. A primeira a sair foi a glucoamilase e a segunda a sair foi a $\alpha$-amilase. Fez-se uma cromatografia dos produtos da hidrólise das duas frações enzimáticas isoladas. No cromatograma, o substrato foi o amido e os produtos de hidrólise detectados foram, na fração 1 , a glicose e, na fração 2, a glicose e a maltose.

Foi estabelecido um padrão de hidrólise por um longo tempo. Constatando-se que depois de 4 horas a glucoamilase provoca hidrólise completa do glicogênio e do amido. Depois de 10 horas, restaram somente 15\%, conforme demonstra o Gráfico 1 e o Gráfico 2.

Tabela 1 - Resumo da purificação da glucoamilase no filtrado de cultura de Aspergillus fumigatus

\begin{tabular}{|l|c|c|c|}
\hline \multicolumn{1}{|c|}{$\begin{array}{c}\text { PASSOS DE } \\
\text { PURIFICAÇÃO }\end{array}$} & $\mathrm{V}(\mathrm{ml})$ & ATIVIDADE $(\mathrm{U} / \mathrm{ml})$ & $\begin{array}{c}\text { PROTEÍNA TOT AL } \\
(\mathrm{mg} / \mathrm{ml})\end{array}$ \\
\hline Filtrado inicial Cultura & 400 & 18,75 & 1,0175 \\
\hline $\begin{array}{l}\text { Precipitação com } \\
\text { Sulfato amônio 75\% do } \\
\text { filtrado inicial de } \\
\text { cultura. }\end{array}$ & 17 & 330,5882 & 5,1764 \\
\hline Eluído do DEAE & 56 & 33,4821 & 0,2232 \\
\hline
\end{tabular}


12

Gráfico 1 - Padrão de hidrólise do amido por um longo tempo, até a sua hidrólise completa

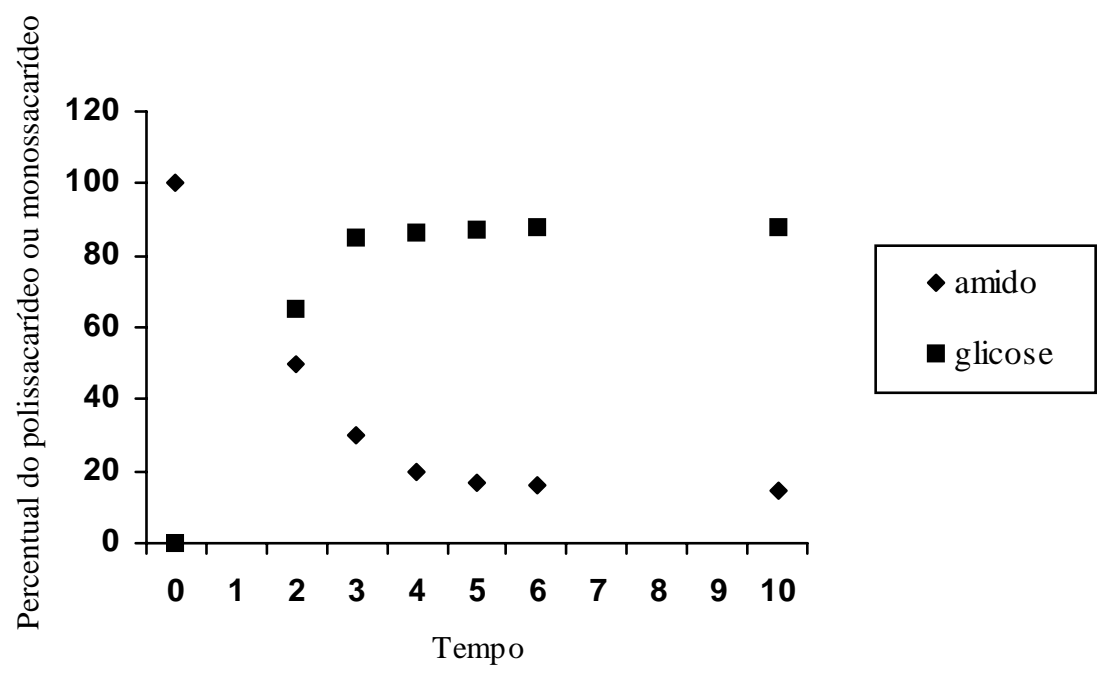

Gráfico 2 - Padrão de hidrólise do glicogênio por um longo tempo, até a sua hidrólise completa

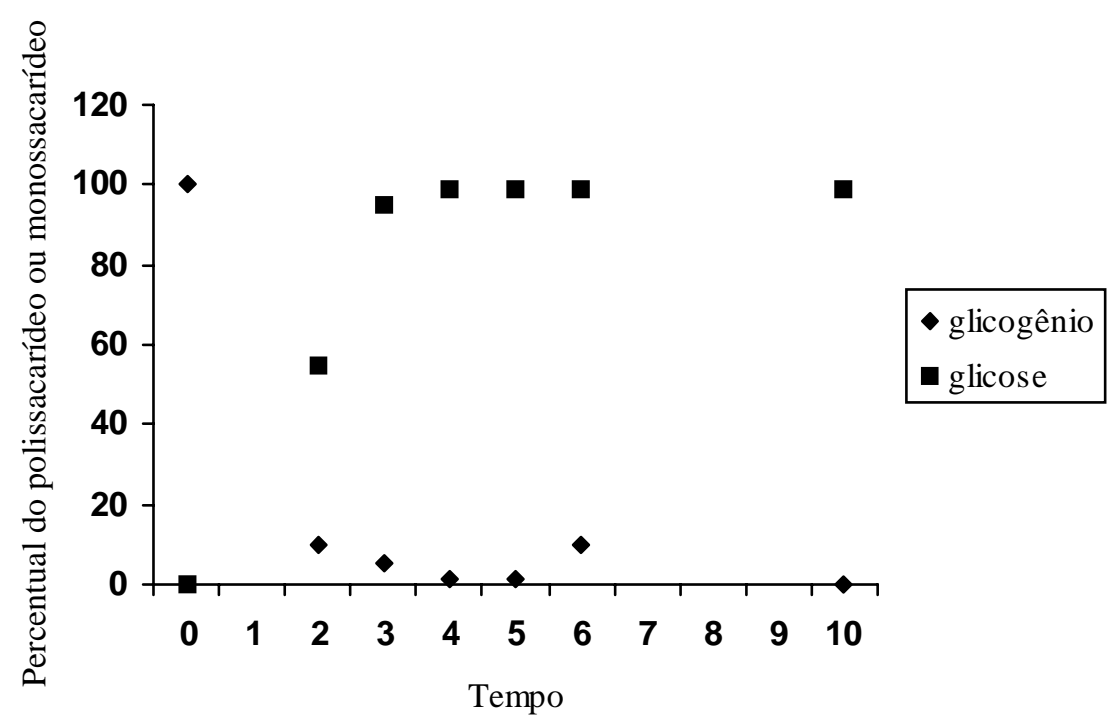

PUBLICATIO UEPG - Biological and Health Sciences, 6 (1): 7-19, 2000. 


\subsection{Características físico-químicas}

A temperatura ótima foi determinada em $65^{\circ} \mathrm{C}$ (Gráfico 3) e o pH ótimo foi determinado como pH 5,0 (Gráfico 4). Como efeito dos íons inibidores sobre a enzima, foi constatada sua inibição por vários metais pesados, principalmente $\mathrm{o} \mathrm{Hg}^{+2}, \mathrm{~Pb}^{+2}, \mathrm{Fe}^{+2}$, mas o quelante EDTA não a inibe, e a presença de cálcio a estimula timidamente (ver Tabela 3).

A especificidade do substrato foi testada para 7 di, oligo e polissacarídeos, sendo que somente o amido, a amilose e a amilopectina sofreram grande hidrólise enzimática (Tabela 2). A rafinose e lactose sofreram uma pequena hidrólise enzimática, celobiose e PMP $\alpha$-glicosídeo não a sofreram.

Depois de 60 minutos, a atividade hidrolítica da glucoamilase sobre o amido gelatinizado continuava altíssima (43,35 U/ml), enquanto a atividade de enzima sobre o amido cru $(1,58 \mathrm{U} / \mathrm{ml})$ representava somente $3 \%$ da atividade enzimática sobre o amido gelatinizado.

O segundo teste de hidrólise de amido cru, desta vez sob um longo período de incubação e usando o complexo amilolítico (glucoamilase e $\alpha$ amilase), mostrou que não ocorreu hidrólise. No tempo 0 , a atividade enzimática foi: controle $(0,12 \mathrm{U} / \mathrm{ml})$ e amostra $(0,84 \mathrm{U} / \mathrm{ml})$; e depois de 36 horas era: controle $(0,12 \mathrm{U} / \mathrm{ml})$ e amostra $(0,84 \mathrm{U} / \mathrm{ml})$.

Gráfico 3 - Efeito da temperatura sobre a glucoamilase extracelular de $A$. Fumigatus

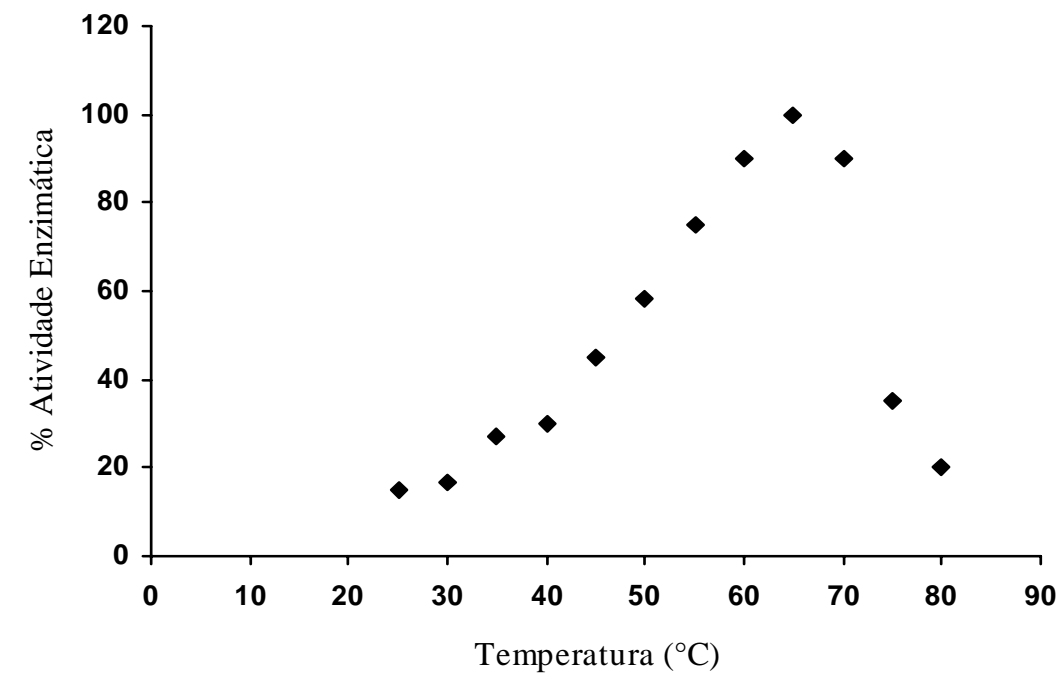

PUBLICATIO UEPG - Biological and Health Sciences, 6 (1): 7-19, 2000. 
Gráfico 4 - Efeitos do pH sobre a atividade da glucoamilase extracelular de $A$. Fumigatus

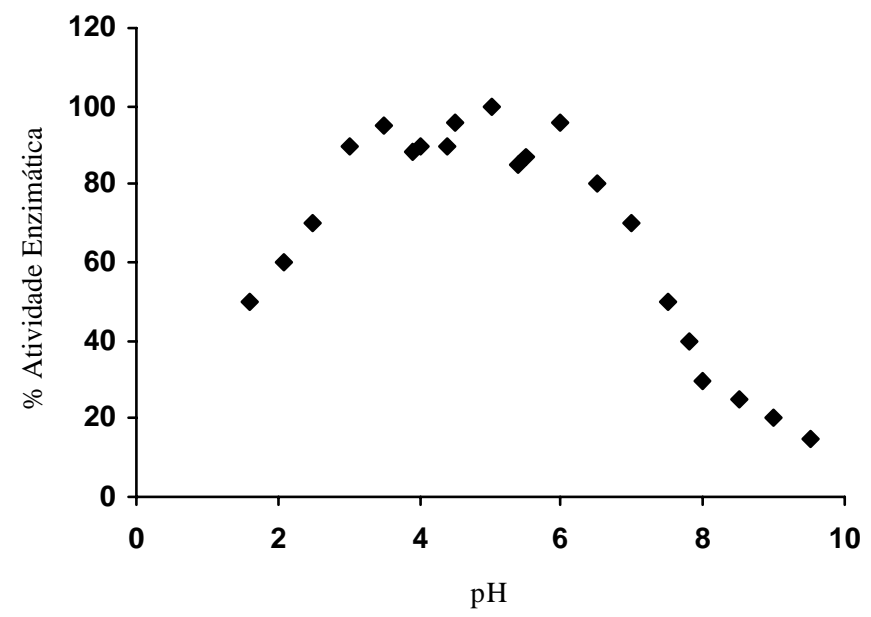

Tabela 2 - Especificidade de substrato da glucoamilase no filtrado de cultura de Aspergillus fumigatus. A especificidade de substrato é expressa como porcentagem de hidrólise de cada substrato para aquela obtida com amido.

\begin{tabular}{|l|c|}
\hline \multicolumn{1}{|c|}{ SUBSTRATO } & $\begin{array}{c}\text { PADRÃO RELATIVO DE } \\
\text { HIDROLISE (\%) }\end{array}$ \\
\hline Amido & 100 \\
\hline Amilose & 93 \\
\hline Amilopectina & 85 \\
\hline Lactose & 4,47 \\
\hline Rafinose & 2.8 \\
\hline Celobiose & n.d. \\
\hline PNP $\alpha$ glicosídeo & n.d. \\
\hline
\end{tabular}

Obs: n.d., significa não detectado. 
Tabela 3 - O efeito de possíveis ativadores ou inibidores da enzima glucoamilásica de Aspergillus fumigatus

\begin{tabular}{|l|c|c|}
\hline $\begin{array}{l}\text { ÍON METÁLICO OU } \\
\text { INIBIDOR }\end{array}$ & CONCENTRAÇÃO (mM) & $\begin{array}{c}\text { ATIVIDADE } \\
\text { RELATIVA \% }\end{array}$ \\
\hline Nenhum & - & 100 \\
\hline $\mathrm{ZnSO}_{4}$ & 10 & 107,5 \\
\hline $\mathrm{MnSO}_{4}$ & 10 & 90,3 \\
\hline EDTA & 10 & 102,8 \\
\hline $\mathrm{FeSO}_{4}$ & 10 & 18,9 \\
\hline $\mathrm{Cl}_{2} \mathrm{Mg}$ & 20 & 124,4 \\
\hline $\mathrm{Cl}_{2} \mathrm{Mg}$ & 50 & 96,5 \\
\hline $\mathrm{Cl}_{2} \mathrm{Mg}$ & 100 & 99,1 \\
\hline $\mathrm{Cl}_{2} \mathrm{Mg}$ & 10 & 94,3 \\
\hline $\mathrm{CaCl}_{2}$ & 10 & 110,3 \\
\hline $\mathrm{CuSO}_{4}$ & 10 & 98,9 \\
\hline $\mathrm{HgCl}_{2}$ & 10 & 0,21 \\
\hline $\mathrm{PbNO}_{3}$ & 10 & 77,4 \\
\hline $\mathrm{CoCl}_{2}$ & 10 & 97,5 \\
\hline $\mathrm{NaCl}$ & 10 & 100,2 \\
\hline $\mathrm{KCl}^{\mathrm{NH}} \mathrm{Cl}$ & 10 & 109,2 \\
\hline
\end{tabular}

\section{Discussão e conclusão}

A glucoamilase de A. fumigatus cultivada em meio líquido Voguel com farelo de aveia mostrou ser mais fácil de purificar, envolvendo poucos passos de purificação, que as glucoamilases de outros fungos ou meios de cultura (ABE et al., 1988; BERGMANN et al., 1988; PLANCHOT e 
COLONNA, 1995; FUTATSUGI et al., 1993; SPEKCA et al., 1991; GHOSH et al., 1991; BHELLA e ALTOSSAR, 1984; TOSI e TERENZI, 1993; ALI et al., 1994; SHAHA et al., 1993).

Nesta purificação foi obtida uma fração que foi testada quanto ao $\mathrm{pH}$ ótimo de ação, sendo que o valor obtido é parecido com o de outras glucoamilases de microorganismos (FUTATSUGI et al., 1993; TOSI e TERENZI, 1993; SPEKCA et al., 1991; BROWN et al., 1990; ALI et al., 1990).

A temperatura ótima de ação da glucoamilase mostrou-se relativamente alta em comparação a 7 fungos, já pesquisados e descritos na literatura, que têm suas enzimas amilolíticas (glucoamilase) com temperatura ótima mais baixa (FUTATSUGI et al., 1993; TOSI e TERENZI, 1993; BHELLA e ALTOSSAR, 1984; SHAHA et al., 1993; ALI et al., 1990).

O efeito de íons metálicos sobre a glucoamilase varia muito de uma para outra, mas em geral, metais pesados a inibem, como neste caso os $\mathrm{Hg}^{+2}, \mathrm{~Pb}^{+2}, \mathrm{Fe}^{+3}, \mathrm{o} \mathrm{Ca}^{+2}$; às vezes estimulam a sua atividade enzimática, mas neste caso o estímulo foi pouco acima do padrão (verificado para amido somente) (GHOSH et al., 1991; ALI e HOUSSAIN, 1991; ALI et al, 1994; SHAHA et al., 1993; BHELLA e ALTOSSAR, 1984, SPECKA et al., 1991).

Devido ao fato de o único produto de hidrólise da glucoamilase ser a glicose, comprova-se a classificação com uma enzima amilolítica glucoamilásica. De acordo com os resultados dos testes de especificidade de substrato, a glucoamilase foi capaz de hidrolisar ligações do tipo a-1-6 (amido, amilopectina e glicogênio).

Os dados da hidrólise sobre o amido cru e gelatinizado mostram que a enzima era incapaz de adsorver e hidrolisar o amido cru, provavelmente devido à sua insolubilidade na água (pois o amido cru em água forma uma suspensão, para dissolvê-lo em solução, é necessário fervê-lo).

Para comprovar essa incapacidade de hidrólise foi feito o segundo teste, desta vez por um longo tempo (36 horas) e os resultados comprovaram essa incapacidade.

Recebido para publicação em 08/02/2000.

Aceito para publicação em 15/09/2000. 
Apoio:UEM (CNPq)

\begin{abstract}
This study aims at biochemically characterizing an extra-cellular amylatic enzyme of a heat-tolerant soil fungus (Aspergillus).
\end{abstract}

Key words: fungus; amylase; biochemical characterization

Endereço para contato: William Brandani da Silva

R. Pioneiro Oscar Antunes, 127 - Vila Esperança

87020-570 - Maringá - Pr

\title{
REFERÊNCIAS
}

1 ABE, J.; BERGMANN, F. W.; OBATA, K.; HIZUKURI, S. Production of the raw-starch amylase of Aspergilus k-27. Appl. Microbiol. Biot., v. 27, p. 447-450, 1988.

2 ALI, N. M.; MARY, J.; KALYANASUNDARAM, I. Extracellular amylase in myxomycete plasmodia and its fate during differentation. Mycologia, v. 96, n. 11, p. 990-992, 1992.

3 ALI, S.; MALEK, S.; HOSSAIN, Z. Purification and characterization of a thermostable glucoamylase from a Myrothecium isolate. Journal of Applied Bacteriology, v. 76, p. 210-215, 1994.

4 ALI, S.; HOSSAIN, Z. Characterization of glucoamylase form Aspergillus terreus. Journal of Applied Bacteriology, v. 71, p. 44-146, 1991.

5 ALI, S.; HOSSAIN, Z.; MAHMOOD, S.; ALAM, R. Purification of glucoamylase form Aspergillus terreus. World J. Microb. Biot., v. 6, p. 431-433, 1990.

6 BERGMEYER, H. U.; BERNT, E. Methods of enzimatic analysis, vol. 3. New York: Verlag Academic Press, 1974. 1215 p.

7 BERGMANN, F. W.; ABE, J.; HIZUKURI, S. Selection of microoganisms which 
produce rawstarch degrading enzymes. Appl. Microbiol. Biot., v. 27, p. 443-446, 1988.

8 BHELLA, R.; ALTOSSAR, H. Purification and some properties of the extracellular $\alpha$-amylase from Aspergillus awamori. Can. J. Microbiol., v. 31, p. 149-153, 1984.

9 BROWN, S.; CONSTANTINO, H. R.; KELLY, R. M. Characterization of amylolytic enzyme activities associated whith the hyperthermophilic Archaebacterium pyrococcus furiosus. Appl. Environ. Microb., v. 56, n. 7, p. 1985-1991, 1990.

10 DAVIS, B. J. Disc eletrophoresis II method application to human serum proteins. Annals of New York Acad. of Sci., v. 121, p. 404-427, 1964.

11 DUBOIS, M.; GILLES, K. A.; HAMILTON, J. K.; REBERS, P. A.; SMITH, F. Colorimetric method for determination of sugars and related substances. Anal. Chem., v. 28, n. 3, p. 350-356, 1956.

12 FUTATSUGI, M.; OGAWA, I.; FUKUDA, H. Purification and properties of two forms of glucoamylase from scharomycopsis fibuligera. J. Ferment. Bioeng., v. 76, n. 6, p. 521-523, 1993.

13 GAILLARDY, B. D. E. Use of unneutralized hydrolysaten in paper cromatography of sugar. London : Nature, v. 171, 1953. 150 p.

14 GHOSH, A.; CHATTERJEE, B.; DASS, A. Purification and characterization of glucoamylase of Aspergillus terreus Na-170 mutant. J. Appl. Bacteriol., v. 71, p. 162-169, 1991.

15 HIZUKURI, S.; BERGMANN, F. W.; ABE, J. Selection microorganisms which produce raw-starch degrading enzymes. Appl. Microbiol. Biot., v. 27, p. 443-446, 1988.

16 LOWRY, R.; ROSEBROUGH, N.; FARR, A. L.; RANDALL, P. Protein measurement with the folin phenol reagent. J. Biol. Chem., v. 193, p. 265-275, 1951.

17 MAYER, F. C.; LARNER, J. Substrate cleavage point of the $\alpha$-and $\beta$-amylases. J. Am. Chem. Soc., v. 81, n. 1, p. 188-193, 1959. 
18 MONTENECOURT, B. S.; EVELEIGH, D. E. Preparation of mutants of Thichoderma reesei with enhanced cellulase production. Appl. Environ. Microb., v. 34, p. 777-784, 1977.

19 PERALTA, R. M.; DOMINGUES, C. M. Production of amylase by soil fungi and partial biochemical characterization of amylase of a selected strain (Aspergilus fumigatus). Can. J. Microbiol., v. 39, p. 681-685, 1993.

20 PLANCHOT, V.; COLONNA, P. Purification and characterization of extracellular $\alpha$-amylase form Aspergillus fumigatus. Carbohyd. Res., v. 272, p. 97-109, 1995.

21 ROLAND, B. Comparative study of external and internal $\beta$-glucosidases and glucoamylase of Arxula adenivoras. Journal Basic Microbiology, v. 31, n. 6, p. 423-428, 1991.

22 SHAHA, B. C.; SILMAN, R. W.; BOTHAST, R. J. Amylolytic enzymes produced by a color variant strain of Aureobasidim pullulans. Curr. Microbiology, v. 26, p. 267-273, 1993.

23 SPECKA, U.; MAYER, F.; ANTRANIKIAN, G. Purification and properties of a thermoactive glucoamylase from Crostridium thermoactive. Appl. Environ. Microb., v. 57, n. 8, p. 2317-2323, 1991.

24 TOSI, L. R. O.; TERENZI, H. F. Purification and characterization of an extracellular glucoamylase from the thermophilic fungus Humicola grisea var. Thermoidea. Can. J. Microbiol., v. 39, p. 846-852, 1993.

25 WEBER, K.; OSBORN, M. The reability of molecular weight determination by sodium dodecyl sulphate polyacrylamide gel electrophoresis. J. Biol. Chem., v. 244, p. 4406-4412, 1969.

26 WILSON, J. J.; INGLEDEW, W. M. Isolation and characterization of Schawanniomyces alluvius amylolytic enzymes. Appl. Environ. Microb., v. 44, n. 2, p. 301-307, 1982. 